\title{
Ratio of Excess ED ILI Visits to Seroprevalence, Influenza A/H1N1 Infection, FL, 2009
}

\author{
Richard Hopkins ${ }^{\star 2,1}$, Aaron Kite-Powell ${ }^{1}$, Kate Goodin ${ }^{1}$ and Janet J. Hamilton ${ }^{1}$ \\ 'Epidemiology Bureau, Florida Department of Health,, Tallahassee, FL, USA; ${ }^{2}$ University of Florida, Gainesville, FL, USA
}

\section{Objective}

To estimate the number of infections due to the novel 2009 influenza $\mathrm{A} / \mathrm{H} 1 \mathrm{~N} 1$ virus corresponding to each $\mathrm{ED}$ visit for ILI in a four-county area of Florida. Knowing such ratios, one could (in future similar situations) estimate the cumulative number of infections due to a novel influenza virus in a population.

\section{Introduction}

A seroprevalence survey carried out in four counties in the Tampa Bay area of Florida (Hillsborough, Pinellas, Manatee and Pasco) provided an estimate of cumulative incidence of infection due to the 2009 influenza A (H1N1) as of the end of that year's pandemic (1). During the pandemic, high-level decison-makers wanted timely, credible forecasts as to the likely near-term course of the pandemic. The cumulative percentage of people who will be infected by the end of the epidemic can be estimated from the intrinsic reproductive number of the viral strain, its $\mathrm{R}_{0}$, which can be measured early in the epidemic (2). If the current cumulative number of infections can be estimated, then one can determine what fraction of the eventual total number of infected people have already been infected.

\section{Methods}

Excess emergency department (ED) visits for influenza-like illness (ILI) during the pandemic period (compared to the four nonpandemic years 2007, 2008, 2010, and 2011) were estimated using the ESSENCE-FL syndromic surveillance system for the four-county area. For each week, the percentage of visits that were for ILI, by age group, was compared between 2009 and the average of the other four years. The difference, the excess in percent ILI, was then applied to the observed number of ILI visits for each week and age group to calculate the excess number of visits. These excess visits were summed for the epidemic period, and compared to the estimated number of infected residents of the four-county area obtained by applying the prevalence from the serosurvey to the census population of the four-county area, by age group.

\section{Results}

There were an estimated 44 infections for every ILI ED visit. Agespecific ratios rose from 19.7 to 1 for children aged $<5$ years to $45.4: 1$ for those aged 5 to 17 , to $47.3: 1$ for those aged 18 to $24,36.8$ for those aged 25 to $49,55.4$ for those aged 50 to 64 , and 143.8 to 1 for persons aged $>64$ years. The proportion of infections by age group is similar but not identical to the proportion of excess ED visits. For example, $13.1 \%$ of excess ED visits were for children under age 5, while $9.7 \%$ of estimated infections were in that age group. Persons aged 65 years and older, accounted for $2.3 \%$ of excess ED visits and $6.5 \%$ of infections.

\section{Conclusions}

These ratios provide a way to estimate cumulative incidence of influenza in an epidemic, using excess numbers of ILI visits to emergency departments. These can be used in real time for planning and forecasting, when carrying out timely seroprevalence surveys is not practical. Syndromic surveillance data allow age and geographic breakdowns in estimates of ILI visits and cumulative infection rates. If $R_{0}$ has been estimated independently, then the seroprevalence at which transmission will slow and stop can be compared to the current prevalence estimated from ED visits using these ratios. Similar ratios should be calculated elsewhere if both population-based ED visits for ILI and seroprevalence data for an epidemic strain of influenza are available.

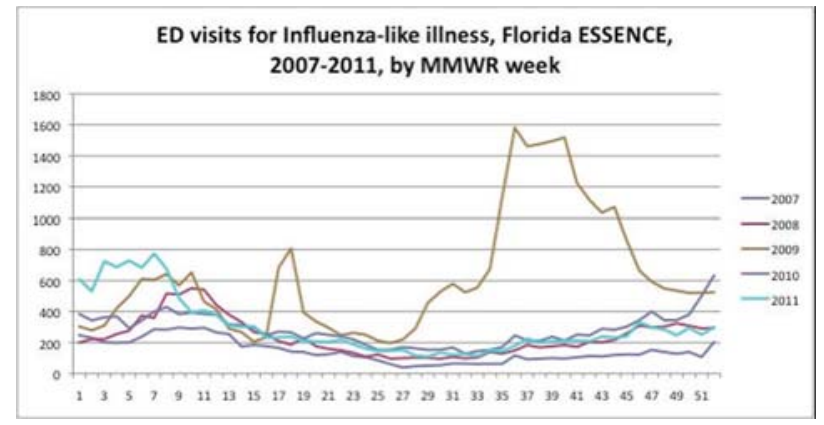

Influenza-like illness visits to Florida emergency departments by week, 2007 to 2011 .

\section{Keywords}

Influenza; prevalence; emergency department visits

\section{References}

(1) Cox CM, Goodin K, Fisher E, et al. Prevalence of 2009 Pandemic Influenza A (H1N1) Virus Antibodies, Tampa Bay Florida November-December, 2009. PLoS ONE 2012 6(12): e29301. oi:10.1371/journal.pone.0029301

(2) Nokes DJ, Anderson RM (1988) The use of mathematical models in the epidemiological study of infectious diseases and in the design of mass immunization programmes. Epidem. Inf 1988; 101, 1-20

\section{*Richard Hopkins \\ E-mail: hopkinsrs@comcast.net}

